\title{
Preventive measures against drug and alcohol addiction as an important factor in future military pilot personality development Nikolayeva N. ${ }^{1}$, Aldoshin V. ${ }^{2}$, Dashkov E. ${ }^{3}$ \\ Профилактическая работа о вреде наркомании и алкоголизма как важный фактор развития личности будущего военного летчика Николаева Н. И. ${ }^{1}$, Алдошин В. В. ${ }^{2}$, Дашков Э. Ш. ${ }^{3}$
}

\author{
${ }^{1}$ Николаева Наталья Ивановна / Nikolayeva Natalya - преподаватель, \\ кафедра иностранных языков; \\ ${ }^{2}$ Алдошин Владимир Викторович / Aldoshin Vladimir - курсант; \\ ${ }^{3}$ Дашков Эдуард Шамилевич / Dashkov Eduard-курсант, \\ Краснодарское высшее военное авиачионное училище летчиков имени Героя Советского Союза А. К. Серова, г. Краснодар
}

\begin{abstract}
Аннотация: статья посвящена проблеме развития личности будущего военного летчика посредством профилактической работь по предотвращению отрищательного влияния наркомании и алкоголизма на здоровый образ жизни курсантов военного авиационного вуза.

Abstract: the article deals with the future military pilot personality development by means of preventive measures against adverse consequences of drug and alcohol addiction on the military aviation institute cadets' healthy lifestyle.
\end{abstract}

Ключевые слова: военный авиаџионный вуз, военно-научная секиия (ВНС), ВКС (Воздушно-космические силь) Российской Федерации, деятельность ОДКБ (Организация Договора о коллективной безопасности) по противодействию незаконному обороту наркотиков, конференция по иностранному языку, здоровый образ жизни, обновленная Стратегия наџиональной безопасности Российской Федерации, профилактическая работа о вреде наркомании и алкоголизма, развитие личности военного летчика.

Keywords: military aviation institute, military scientific section, Russian Aerospace Forces, activities of Collective Security Treaty Organization (CSTO) to counter drug traffic, foreign language conference, healthy lifestyle, updated Russian Security Strategy, preventive measures against drug and alcohol addiction, future military pilot personality development.

Проблема профилактики наркомании и алкоголизма в современных Вооруженных силах является важной частью работы по формированию личности будущего военного летчика, его взглядов на жизнь, развитию морально-деловых качеств, успешному продвижению по карьерной лестнице. От того, как будет осуществлена такого рода деятельность, будет зависеть профессиональная пригодность будущего лётчика ВКС как офицера и гражданина Российской Федерации. По мнению И. Ф. Иоаниди, «во время обучения в военном вузе на 1-2 курсах курсанты сами являются объектами профилактической работы через информирование о вреде наркотиков, правовое воспитание, привитие потребности в здоровом образе жизни и отрицательного отношения к наркотикам» [1, с. 64].

Наркомания - это хроническое заболевание, которое характеризуется навязчивым использованием вызывающих зависимость веществ. Несмотря на негативное воздействие на человека и общество, склонность к наркотикам и алкоголю становится международной тенденцией в образе жизни, которая одинаково распространена в богатых и бедных странах. Зависимость от алкоголя, наркотиков и курения сигарет теперь рассматривается как главная проблема здравоохранения. У других форм зависимости, включая компьютерные игры, азартные игры, еду также есть серьезные последствия на здоровье человека и общества, но наркотики особенно глубоко воздействуют на нервную систему, особенно мозг. Некоторые из наркотических веществ, такие как опиум, марихуана, кокаин, никотин, кофеин, мескалин и псилоцибин, получают из естественных источников, а другие являются синтетическими или дизайнерскими наркотиками. Кроме того, некоторые из веществ, такие как алкоголь и никотин, законны, в то время как у некоторых других, которые доступны по рецепту, есть потенциал вызывать зависимость у людей группы риска. Множество веществ, вызывающих зависимость, незаконны в большинстве стран, поэтому этот фактор питает распространение и торговлю запрещенными веществами, которые часто связываются с преступной деятельностью. Использование наркотических веществ вызывает эйфорию, состояние благополучия и видимость хорошего самочувствия, которые могут привести к физической и психологической зависимости. Синдром отказа происходит, когда человек пытается прекратить использование вызывающих зависимость веществ, и это приводит к циклу зависимости. Механизм, связанный с циклом зависимости, включает нейронную адаптацию или повышение возбудимости, при приеме веществ, вызывающих зависимость. Многие факторы также связаны с зависимостью, включая доступность, стоимость, влияние окружающих и генетические особенности человека. Для лечения наркомании и алкоголизма используется огромное количество терапевтических методов. Однако повторное возобновление приема препарата после периода воздержания считается главным препятствием в лечении наркомании. Сегодня результаты лечения зависимости от наркотиков и алкоголя лекарственными препаратами в основном являются неутешительным, поэтому необходимы новые методы терапии. Для курсантов высших военных училищ такими методами, безусловно, должны быть здоровый образ жизни и интенсивные занятия спортом, а также постоянные разъяснительные профилактические мероприятия о 
губительном, а порой безвозвратном воздействии наркотиков на все жизненно важные органы человеческого тела. Предотвратить даже желание попробовать что-то новое в ощущениях путём принятия наркотических средств можно и нужно, несмотря на влияние на некоторых индивидуумов как генетической предрасположенности, так и окружающей среды.

Знание проблем и последствий употребления наркотиков является важным и неотъемлемым аспектом профилактической работы с будущими офицерами-лётчиками ВКС, так как они сами будут обязаны в будущем проводить подобную работу со своими подчиненными. От того, насколько у самого офицера будут сформированы профессиональные компетенции, будет зависеть его взаимодействие с личным составом в процессе информирования по данной проблеме.

Мы разделяем точку зрения доктора педагогических наук А. В. Пономарева о том, что «междисциплинарный подход, позволивший выявить различные дисциплинарные контексты исследования процесса воспитательной деятельности вуза, позволил сформировать различные исторически определенные модели, совокупно описывающие взаимное влияние процесса воспитания и социокультурных условий» [2, с. $25]$.

Участие курсантов военно-научной секции кафедры иностранных языков в обсуждении проблемы вреда наркотической зависимости в рамках конференции по иностранному языку «Threats and Challenges of the Modern World» (2015 г.) дало возможность с помощью иноязычного общения обратиться к воспитательной и развивающей стороне образовательного процесса, к несомненной целесообразности поднимать вопросы, касающиеся государственной и общественной безопасности.

В процессе участия в конференции курсанты пришли к пониманию того, что важной задачей профилактики наркомании в Вооруженных силах вообще и в авиационном вузе в частности является грамотное информирование военнослужащих о видах наркотических средств и их влиянии на здоровье. Также было акцентировано внимание на сопоставительной характеристике борьбы разных стран с наркозависимостью населения, роли России в решении этой проблемы в рамках современной геополитики. Противодействие наркоугрозе является одним из ключевых элементов обновленной Стратегии национальной безопасности Российской Федерации, утвержденной Президентом Российской Федерации 31.12.2015 года [3]. В Указе Президента особая роль отводится деятельности ОДКБ по предотвращению наркотрафика через границы государств-стратегических партнеров Российской Федерации.

Авторами статьи были исследованы аутентичные англоязычные Интернет-ресурсы, а также некоторые работы отечественных исследователей для осмысления масштабности проблемы наркомании и алкоголизма во всём мире и в Российской Федерации в том числе.

Наркотики были частью культуры в США с середины прошлого века. Популяризированные в 1960-х музыкой и средствами массовой информации, они вторгаются во все аспекты современного общества.

Многие люди даже не осознают всю опасность ситуации, когда начинают принимать наркотические средства. Одним из факторов, которые могут быть причиной того, почему человек стал наркоманом, является окружающая среда: «A person's environment includes many different influences, from family and friends to economic status and general quality of life» («Среда человека включает в себя множество различных воздействий: от семьи и друзей до экономического статуса и общего качества жизни в целом») (Переведено нами. Н.Н.) [4].

Именно дисбаланс жизненных ценностей и влияние окружения могут привести к тому, что человек начнет искать возможность ухода от реальной действительности, а затем, как следствие, принимать наркотики, чтобы не ощущать свою безысходность в жизни.

Приблизительно 208 миллионов человек на международном уровне потребляют наркотики. В Соединенных Штатах Национальный обзор употребления наркотиков за 2007 год выявил, что 19.9 миллиона американцев (или 8\% населения старше 12 лет) использовали запрещенные наркотики за месяц до проведения исследования.

Наиболее используемый и злоупотребляемый препарат в США — алкоголь. Связанные с алкоголем автомобильные катастрофы - вторая главная причина подростковых смертей в Соединенных Штатах.

Чаще всего употребляемый запрещенный наркотик - марихуана. Согласно Всемирному докладу о наркотиках Организации Объединенных Наций 2008 года, приблизительно 3.9\% населения в мире в возрасте от 15 до 64 лет злоупотребляют марихуаной.

Молодые люди сегодня подвергнуты наркотической зависимости более чем когда-либо. На основании данных Центра США по контролю и профилактике заболеваний в 2007 году 45\% учеников средней школы пили алкоголь и $19.7 \%$ курили марихуану на протяжении месяца.

В Европе недавние исследования среди 15- и 16-летних подростков показывают, что использование марихуаны варьируется от 10\% до 40\% с самыми высокими показателями в Чешской Республике (44\%), Ирландии (39\%), Великобритании (38\%) и Франции (38\%). В Испании и Великобритании использование кокаина среди 15-, 16-летних составляет от $4 \%$ до $6 \%$. Использование кокаина среди молодых людей повысилось в Дании, Италии, Испании, Великобритании, Норвегии и Франции. Марихуана обычно свертывается в сигарету. Она может также завариваться как чай или смешиваться с едой или куриться через водяную трубу, названную бонг.

Марихуана занимает третье место (16\%) среди веществ, которые разрешены для медикаментозного лечения в Соединенных Штатах Америки. Согласно Национальному обзору потребления наркотиков дети, которые чаще используют марихуану, будут почти в четыре раза агрессивнее. Эти дети совершают кражи с 
вероятностью в 5 раз выше, чем те, кто не употребляет траву. Марихуана оказывает эффект мощнее, чем раньше. Улучшение методов сортировки семян привело к большему усилению воздействия на организм наркотического вещества. В результате этого резко увеличилось количество вызовов неотложной помощи молодыми курильщиками, связанных с употреблением данного наркотика.

Поскольку толерантное отношение к данному веществу растет, марихуана может побудить зависимых употреблять более сильнодействующие наркотики, чтобы достигнуть того же самого эффекта. Когда эффекты начинают смягчаться, человек может повернуться к более мощным наркотикам, чтобы избавить себя от нежелательных условий, которые побудили его принять марихуану впервые. Сама марихуана «не подсаживает» человека к другим наркотикам: люди принимают наркотики, чтобы избавиться от нежелательных эмоций. Марихуана маскирует проблему какое-то время (в то время как человек находится под её действием). Когда действие прекращается, проблемы возвращаются с худшими последствиями, чем прежде. Человек может тогда обратиться к более сильнодействующим наркотикам, так как марихуана больше не «работает».

Потеря координации и искажение времени, зрения и слуха, сонливость, покраснение глаз, увеличение аппетита и расслабление мышц - вот неполный перечень отрицательного воздействия марихуаны на человека. Сердечный ритм может ускориться. Фактически, на первом часе курения марихуаны риск сердечного приступа может увеличиться в пять раз. Показатели успеваемости ухудшаются в связи со сниженными вниманием, памятью и ослабленной способностью решать проблемы. Долгосрочное использование наркотика может вызвать психотические симптомы. Марихуана вызывает болезни сердца, легких, симптомы бронхита и снижает иммунитет.

Алкоголь угнетает центральную нервную систему (головной и спинной мозг), убирает запреты и снижает суждения. Употребление большого количества алкоголя может привести к коме и даже смерти. Смешивание алкоголя с лекарствами или кустарными наркотиками чрезвычайно опасно и может быть смертельным. Прием алкоголя влияет на сосуды головного мозга, приводит к потере координации, замедлению реакции, искажению зрения, провалам в памяти и помутнению рассудка. Подростковые тела все еще развиваются, и алкоголь оказывает большее влияние на физическое и умственное состояние молодых людей, чем на взрослых.

Чувство тепла, покраснение кожи, ослабление суждения, отсутствие координации, нечленораздельная речь, ухудшение памяти и потеря чувства реальности указывают на алкогольное опьянение. Алкоголизм обычно приводит к «похмелью», головной боли, тошноте, беспокойству, слабости, а иногда и к рвоте.

Толерантность ко многим неприятным эффектам алкоголя и развитию способности пить больше приводит к ухудшению физического состояния, которое включает повреждение печени и увеличивает риск возникновения болезней сердца. Беременная женщина может родить ребенка с дефектами, которые затрагивают сердце ребенка, мозг и другие главные органы. Человек может стать зависимым от алкоголя. Если кто-то внезапно прекращает пить, может начаться абстиненция. Ее симптомы колеблются от нервозности, бессонницы, потливости и плохого аппетита до конвульсий и иногда смерти. Злоупотребление алкоголем может также привести к повышенной агрессивности и конфликтности.

Кокаин может употребляться орально, через нос или внутривенно шприцем. Крэк употребляется через ингаляцию паров от его нагревания. Кокаин вызывает недолгий интенсивный эффект, который немедленно сопровождается противоположным глубоким чувством депрессии и нервозности и тяги к большему количеству препарата. Люди, которые используют его часто, не едят или не спят должным образом. Они могут испытывать ускоренный сердечный ритм, мышечные спазмы и конвульсии. Препарат может заставить людей чувствовать себя параноиками, сердитыми, враждебными и беспокойными, даже когда они не находятся под его воздействием.

В дополнение к уже упомянутым эффектам кокаин может вызывать раздражительность, перемены настроения, неугомонность, паранойю и слуховые галлюцинации. Толерантность к препарату развивается так чтобы произвести тот же самый эффект, нужно увеличить дозу.

Ломка вызывает тяжелую депрессию, которая становится более глубокой после каждого использования. Это может стать столь серьезным, что человек может пойти на все ради дозы, даже на убийство, а затянувшаяся депрессия может довести до самоубийства.

Кристаллический метамфетамин (денатурат) вдыхают, курят или вводят внутривенно. Низкие дозы употребляются в форме таблетки. Кристаллический денатурат - это форма метамфетамина, который напоминает маленькие фрагменты стекла или солнечных сине-белых скал. На сленге он известен как «лед», «кристалл», «стекло» и. т.д. Это очень сильный и захватывающий искусственный стимулятор, который вызывает агрессию и сильное психотическое поведение. Большинство наркоманов сообщают о том, что хватает одного употребления, чтобы стать зависимым. Это один из самых тяжелых из рассматриваемых наркотиков.

Отрицательные эффекты этого наркотика включают нарушения сна, гиперактивность, тошноту, манию величия, повышенную агрессивность и раздражительность. Он может вызвать потерю аппетита и веса. В более высоких дозах препарат имеет больший «прилив», сопровождаемый повышенным возбуждением, а иногда и насилием. Другие эффекты могут включать бессонницу, замешательство, галлюцинации, беспокойство и паранойю. Метамфетамин может даже вызвать конвульсии, приводящие к смерти.

Увеличенный сердечный ритм и кровяное давление, повреждение кровеносных сосудов в мозге приводят к инсультам или нарушенному сердцебиению, сердечно-сосудистым заболеваниям и смерти. Этот кристаллический денатурат может вызвать повреждение печени, почек и легких. Зависимые могут получить 
повреждение головного мозга, включая ухудшение памяти и неспособность к абстрактному мышлению. Те, кто приходит в себя, обычно подвергаются провалам в памяти и резким переменам настроения.

Героин обычно вводится внутривенно, нюхается или курится. Он быстро вызывает привыкание. Героин быстро попадает в мозг, но заставляет людей медленно думать и реагировать, вызывает трудность при запоминании, ослабляет способность принимать решения.

Введение наркотика может создать риск СПИДа, гепатита и других болезней, передающихся через кровь и вызванных зараженными иглами. Эти проблемы со здоровьем могут быть переданы сексуальным партнерам и новорожденным. Героин - один из наркотиков, которые наиболее часто приводят к смерти от злоупотребления. Насилие и преступления также связаны с его использованием.

Наркоманы имеют затуманенный рассудок, испытывают тошноту и рвоту, повышается их болевой порог. У беременных женщины может случиться выкидыш. Сердечные функции угнетаются, затрудняется дыхание, что может привести к смерти.

Введение героина также приводит к травмированным и/или разрушенным венам, бактериальным инфекциям кровеносных сосудов, сердечных клапанов, нарывам и другим инфекциям мягкой ткани, заболеваниям печени или болезни почек.

Что касается России, в 2015 году органами наркоконтроля в суды направлено 95 уголовных дел по преступлениям, совершенным преступными сообществами (в 2014 году - 108), и 5614 уголовных дел в отношении преступных групп (в 2014 году - 4809). При этом около четверти из них были организованы за пределами Российской Федерации или имели в своей структуре подразделения, находящиеся на территории иностранных государств. По итогам 2015 года, правоохранительными органами расследовано 14,1 тыс. наркопреступлений, совершенных в организованных формах, что на 14,3\% больше, чем в 2014 году. Из них 11,1 тыс. - ФСКН России (рост на 10,2\%), 2,2 тыс. - МВД России (рост на 43 \%) и 0,8 тыс. - иными ведомствами (рост на 8,8\%). Их практические результаты и достигнутая высокая степень координации совместной деятельности компетентных органов различных государств предполагают продолжение взаимодействия на данном направлении. К уголовной ответственности привлечено 13,2 тыс. участников организованных преступных групп и сообществ, что на 18,8 \% превышает показатель за 2014 год, в том числе органами наркоконтроля - 75,6 \%, или около 10 тыс. лиц данной категории (рост на 13,6 \%). Всей правоохранительной системой из оптового оборота (актива оргпреступности) изъято 26,5 тонны наркотиков, при этом на ФСКН России приходится 20,8 тонны. Тем самым только силами органов наркоконтроля предотвращен экономический ущерб на сумму 114 млрд рублей, недопущение попадания наркотического опта для розничной реализации в обществе. В этой связи на 2016 год запланированы активные этапы Региональной антинаркотической операции «Канал» с участием заинтересованных государств Азии и Европы - «Канал Западный заслон» (Республика Беларусь), «Канал - Бастион» (Крым), «Канал - Кордон» (Киргизская Республика), а также иные целевые тематические международные операции. В 2015 году был проведен ряд комплексных международных антинаркотических операций, в числе которых Региональные антинаркотические операции «Канал - Патруль» (Кыргызская Республика), «Канал - Синтетик - Почта» (Российская Федерация, г. Владивосток), «Чистый Каспий», международная специальная антинаркотичесая операция «Мозаика», а также международные антинаркотические учения «ГРОМ-2015» и «Аравийский муссон - 2015».

Борьба с наркотиками и профилактика их употребления являются важной стратегической задачей государства. В отношении военнослужащих, являющихся основной боеготовой силой, необходимо отметить то, что состояние их физического и психического здоровья напрямую влияет на обеспечение обороноспособности страны. Высокий уровень наркотизации населения России остается прямой угрозой безопасности и основным фактором подрыва демографического и социально-экономического потенциала страны. Приём наркотиков для военнослужащих, будущих лётчиков ВКС должен быть непреложным табу.

Профилактическая работа среди молодежи в военных училищах, где идет подготовка офицеров Воздушнокосмических сил страны, которые в будущем будут осуществлять защиту интересов государства, должна проводиться скрупулезно, последовательно и постоянно. Главным подходом к воспитанию будущих летчиков должен являться личностно-ориентированный подход, который основан на социально-деятельностном понимании личности курсанта, свободной от всякого рода зависимостей, являющихся не только непосредственной угрозой здоровья и безопасности отдельного индивидуума, но и всего государства Российского.

\section{Лumepamypa}

1. Иоаниди И. Ф. Профилактика наркомании в Вооруженных силах РФ: проблемы и пути их решения. // Психопедагогика в правохранительных органах. Омск, 2005. № 2 (24). С. 64-65.

2. Пономарев A. B. Социально-педагогическая функция вуза в воспитании современного специалиста: автореф. дис. д-ра пед. наук: 13.00.08. Екатеринбург, 2009. 65 с.

3. Указ Президента РФ от 31 декабря 2015 года № 683 «О Стратегии национальной безопасности Российской Федерации» (Ст. 43, 44, 90). [Электронный ресурс]. Режим доступа: https://rg.ru/2015/12/31/nac-bezopasnostsite-dok.html/ (дата обращения 24.10.2016). 
4. Understanding Drug Use and Addiction. [Электронный ресурс]. Режим https://www.drugabuse.gov/publications/drugfacts/understanding-drug-use-addiction/ (дата 24.10.2016).

доступа: обращения 